Article

\title{
Experimental and Simulation Study on Tool Life Models in Drilling of Forging Brass Using Uncoated-WC and AlCrN Coated-WC Tools
}

\author{
Manit Timata and Charnnarong Saikaew * \\ Department of Industrial Engineering, Faculty of Engineering, Khon Kaen University, Khon Kaen 40002, \\ Thailand; manitt@asu.ac.th \\ * Correspondence: charn_sa@kku.ac.th
}

Received: 30 October 2019; Accepted: 11 December 2019; Published: 13 December 2019

\begin{abstract}
Burr is an undesirable phenomenon occurring in drilling operation which is one of the essential operations in the machining industry since it is directly influencing the operating costs. Exit burr height $(\mathrm{EBH})$ values as the function of drilling time during drilling the specific holes of the forging brass workpieces used for producing the water-valve components with the uncoatedtungsten carbide (WC) and the AlCrN coated-WC drills were discussed. The data sets of drilling time, corresponding to EBH values at the appropriate criterion were used to develop the tool life models in terms of cutting speed and feed rate using Taylor's equation. Monte Carlo simulation was adopted to study the uncertainty of cutting speed and feed rate on tool life predictions for sensitivity analysis. The results showed that drilling with a low feed rate decreased the averages of EBH. The predicted tool life values of the AlCrN coated-WC drills were higher than those of the uncoated-WC ones based on the results of tool life predictions. The appropriate operating condition of the cutting speed of $60 \mathrm{~m} / \mathrm{min}$ and the feed rate of $0.2 \mathrm{~mm} / \mathrm{rev}$ was recommended for manufacturers in the drilling of the forging brass workpieces using the AlCrN coated-WC drills. Moreover, the predicted tool life values for the uncoated-WC and the AlCrN coated-WC drills were about 600 and $800 \mathrm{~min}$, respectively. This indicated that the AlCrN coated-WC drill increased tool life by $30 \%$.
\end{abstract}

Keywords: drilling; tool life; burr height; Taylor's model; Monte Carlo

\section{Introduction}

Tool life is very important in the machining industry to improve the quality of a cutting tool as well as a machine component. If tool life expires, the reliability of the tool affects quality of the machined parts and productivity. It is one of the important five criteria (tool life, material remove rate, cutting forces, surface finish and chip shape) used for studying the material and cutting tool behaviours during machining [1]. The tool life model can be effectively used to predict tool wear and length of cutting time that the tool can be operated before changing a new tool. Tool life criteria have been adopted for performing tool life models. Generally, tool life criteria used in the cutting operations can be observed from failure of the tool, occurrences of maximum width of the flank wear, the depth and width of crater wear, sound of the tool, type of chip, degradation of machined surface [2].

There have been previous researches on drilling tool life based on various tool life criteria. de Paiva et al. [3] compared the performance of coatings deposited on cemented carbide drills in drilling compacted graphite iron based on tool life criterion of flank wear. They found that the Cr-based coatings ( $\mathrm{AlCrN}$ and TiSiN/AlCrN) had better performance than other ones. Wu et al. [4] also used the flank wear of the drill cutting edge as a tool life criterion in drilling compacted graphite iron with coated carbide drill at the feed rate of $26.5 \mathrm{~mm} / \mathrm{s}$. 
Burr height is another criterion used to develop a tool life model. It is noted that burr is a critical problem of various manufacturing processes, especially drilling operation which is one of the most important operations in the machining industry since it is directly influencing the operating costs. Burr significantly influences productivity. Gillespie [5] stated that burr elimination can account for $30 \%$ of the total operating cost. The deburring procedure after a drilling operation of thousands drilled holes requires a tremendous operating cost to various industries [6]. Drilling operation accounts for approximately $33 \%$ of all cutting operations [7]. Consequently, machined part should be used without the process of deburring. Costa et al. [8] used the burr height of the drill coated with TiAlN as the criterion in drilling of the steel DIN 38MnS6 with two cutting speeds $(45,60 \mathrm{~m} / \mathrm{min})$. They used the average burr height as a function of the drill life levels (in percentage). They found that the average burr height increased with the wear of the drills. The average burr heights for the cutting speed of $45 \mathrm{~m} / \mathrm{min}$ were twice than those for the cutting speed of $60 \mathrm{~m} / \mathrm{min}$.

Some researchers have applied Taylor's equation for the tool life modelling of drilling tools to investigate the effect of drilling parameters on drilled holes. Lukic and Djapic [9] proposed a model relationship between cutting speed and tool life for optimization of the cutting parameter in drilling of various workpieces based on Taylor's extended equation. Shen et al. [10] developed the tool life of spade drills in drilling of ductile materials by varying cutting speeds, feed rates and drill point angles. They showed that the extended Taylor's equation could be used to predict qualitatively and quantitatively the tool life of spade drills with variations of drilling parameters and drill geometry. Astakhov et al. [11] proposed the logarithmic coordinate transformations of the regression equation to investigate the effect of cutting speed, feed rate and cutting fluid flow rate on the drilled holes roughness and roundness, the tool life and the cutting force in deep holes drilling. However, there has been no previous study regarding tool life modelling using Taylor's equation with the burr height criterion in drilling of forging brass.

Timata and Saikaew [12] attempted to systematically investigate the effect of different spindle speeds and feed rates on EBH and drilled diameter during drilling of forging yellow brass with the special uncoated carbide drill. It was found that spindle speed and feed rate on the exit burr height (EBH) and drilled diameter were statistically significant at the level of significance of 0.05 . In addition, the appropriate operating condition of the drilling parameters was obtained based on the results of analysis of variance and response surface methodology. In this work, CNC drilling machine was employed to carry out the experiments under dry condition for making the specific hole of the forging brass workpieces for producing the water-valve components using the uncoated-WC and the AlCrN coated-WC drills. It is noted that $\mathrm{AlCrN}$ was considered to be an alternative coating material for drilling tools due to its excellent properties such as low thermal conductivity, better abrasive wear resistance, low friction coefficient, high hardness, elastic modulus, $\mathrm{H} / \mathrm{E}$ ratio, and bonding condition between coating and the unique carbide substrate [13-15]. Tool life models of both drills were developed in terms of cutting speed and feed rate using Taylor's equation with a maximum EBH value of $0.16 \mathrm{~mm}$ for the tool life criterion based on manufacturer's specifications and customer's requirement. In addition, Monte Carlo simulation was used to investigate the influence of cutting speed and feed rate on tool life predictions for sensitivity analysis and studying the uncertainty of drilling factors on EBH and tool life. Hence, the novel research contributed to the systematic understanding of the sensitivities of tool life predictions for uncertainty assessment of the drilling factors within the $95 \%$ confidence interval due to the inherent variation of the drilling process. Only a few experimental runs were required to formulate the tool life model. Furthermore, this study was simplified by the fact that the running time for the Monte Carlo simulation was less time consuming using the Minitab ${ }^{\circledR}$ software.

\section{Materials and Methods}

Brass is an important material used for various manufacturing purposes. It is used to produce a water-valve component by the forging manufacturing process under real working conditions in a company located in a province of Thailand. Figure 1 shows a water-valve component and its 
dimensions including the specific holes with the diameters of $14.8 \pm 0.15 \mathrm{~mm}$ and $24.5 \pm 0.15 \mathrm{~mm}$. The water-valve component is made from yellow brass (model JIS-C3771). The chemical compositions in wt. $\%$ of the brass consisted of $59.157 \% \mathrm{Cu}, 38.35 \% \mathrm{Zn}, 2.232 \% \mathrm{~Pb}, 0.131 \% \mathrm{Fe}, 0.077 \% \mathrm{Sn}, 0.031 \% \mathrm{Ni}$, $0.022 \% \mathrm{Sb}, 0.010 \% \mathrm{As}, 0.003 \% \mathrm{Mn}, 0.0013 \% \mathrm{Mg}$.

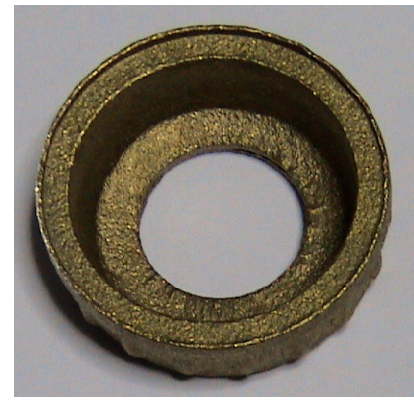

(a)

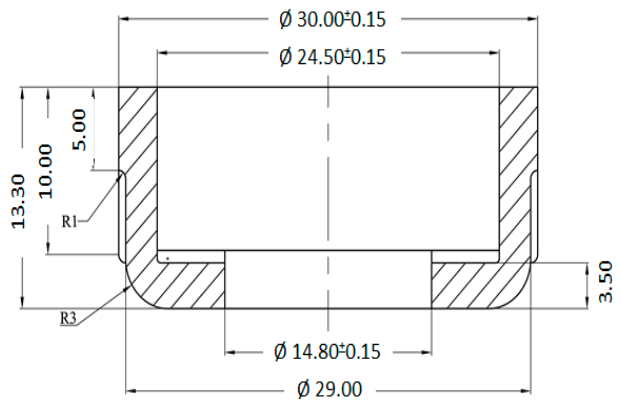

(b)

Figure 1. (a) Photograph of a water-valve component and (b) its dimensions.

Figure 2 shows a schematic drawing of a drill. The drilling tool was designed and manufactured for drilling the specific holes of the water-valve component. The CNC drilling machine (Number Five: model DR-8P) was used for all experiments in this study. A special drill is made of tungsten carbide (WC) and prepared by sintering process (class K20, DIN: DK 255F). The special drills were also coated with AlCrN by magnetron sputtering, filtered cathodic arc (FCA) system equipped with two material targets and the proprietary straight duct filters (Kitagawa (Chon Buri, Thailand) and Nanoshield Co., Ltd.). The drills were cleaned by detergent and sonicated with alcohol for $30 \mathrm{~min}$ and then placed into the FCA chamber followed by evacuation to a base pressure of $5 \times 10^{-3} \mathrm{~Pa}$. The drills were heated to $350{ }^{\circ} \mathrm{C}$ and bombarded with metal ions produced by a filtered cathodic arc under a substrate bias of $1000 \mathrm{~V}$ for $10 \mathrm{~min}$ in order to enhance the adhesion of deposited AlCrN film and remove residual surface impurities. The thickness of the $\mathrm{AlCrN}$ coating measured by a commercial

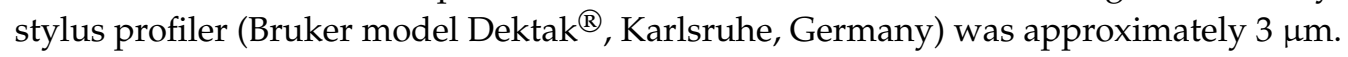
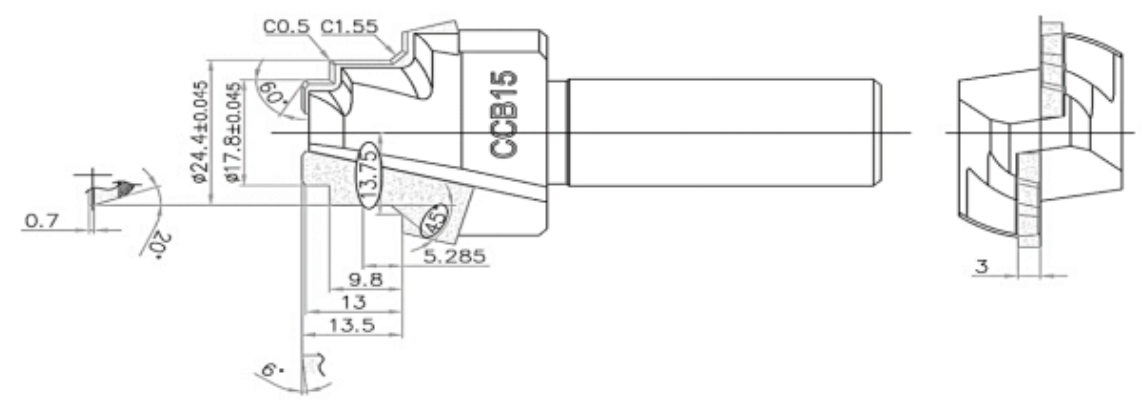

Figure 2. Schematic drawing of a drill.

There has been no previous study of the effect of cutting speed and feed rate on burr formation and tool life in drilling of forging brass with AlCrN coated-WC and other coated drills. However, in this study, the cutting speed and feed rate, and their levels were selected from the tool manufacturer's recommendation and based on the real production process as well as some literature reviews. Some researchers studied the effects of different feed rates and cutting speeds on burr formation [16], drilled hole surface roughness $[11,17]$, tool life $[18,19]$, and tool wear $[20,21]$ during drilling of various materials.

Lin and Shyu [18] improved the cutting performance of drilling stainless steel with coated drills by varying feed rates while Lin [17] studied the effect of cutting speed and feed rate on burr height and surface roughness and found that cutting speed and feed rate were superior to constant feed rate regarding tool life, burr height and surface roughness. Karnik et al. [16] investigated the effect 
of cutting speeds $(8,12,16 \mathrm{~m} / \mathrm{min})$ and feed rates $(0.04,0.08,0.12 \mathrm{~mm} / \mathrm{rev})$ on burr height and burr thickness during the drilling of AISI 316L stainless steel. Wang et al. [19] selected the two cutting speeds $(80$ and $120 \mathrm{~m} / \mathrm{min})$ and two feed rates $(0.14$ and $0.18 \mathrm{~mm} / \mathrm{rev})$ in drilling of $42 \mathrm{CrMo}$ steel with TiN-coated fine grain cemented carbide twist drills. Polli and Cardoso [20] carried out the deep drilling experiments on the forged and heat-treated SAE $4144 \mathrm{M}$ steel using solid cemented carbide twist drills with cutting speeds of 50,65 and $70 \mathrm{~m} / \mathrm{min}$ and feed rates of $0.05,0.12$ and $0.15 \mathrm{~mm} / \mathrm{rev}$. Cardoso et al. [21] selected two cutting speeds and two feed rates in drilling of SAE4144M steel with TiAlN and AlCrN coated drills. They stated that AlCrN coated drill had better performance than TiAlN coated drill based on a significant reduction of adhered material on the drill.

Table 1 shows three cutting speeds $(40,50$ and $60 \mathrm{~m} / \mathrm{min})$ and three feed rates $(0.15,0.20$ and $0.25 \mathrm{~mm} / \mathrm{rev}$ ) for carrying out the drilling experiments using the uncoated-WC and the AlCrN coated-WC drills.

Table 1. Drilling factors and their levels for carrying out the drilling experiments using the uncoated-WC and AlCrN coated-WC drills.

\begin{tabular}{cccc}
\hline \multirow{2}{*}{ Factor } & \multicolumn{3}{c}{ Level } \\
\cline { 2 - 4 } & Low & Middle & High \\
\hline Cutting speed $(\mathrm{m} / \mathrm{min})$ & 40 & 50 & 60 \\
Feed rate $(\mathrm{mm} / \mathrm{rev})$ & 0.15 & 0.20 & 0.25 \\
\hline
\end{tabular}

The CNC drilling machine produced approximately 1000 drilled workpieces for each drilling interval time of $72 \mathrm{~min}$. At this drilling interval time, the drill was taken off the $\mathrm{CNC}$ machine. One hundred samples of drilled workpieces were randomly selected from all drilled workpieces. Then, EBH values of each sample were measured at different three positions using a burr height measuring instrument (Bruker: model Dektak XT) as shown in Figure 3. An average EBH was calculated from the three EBH measurements of each sample and an average EBH of one hundred samples was determined. The averages EBH of each of one hundred samples were collected at every drilling interval time of 72 min until reaching the EBH criterion of $0.16 \mathrm{~mm}$. After EBH determinations were obtained, other new drills were installed in the CNC machine to continue drilling of the workpieces.

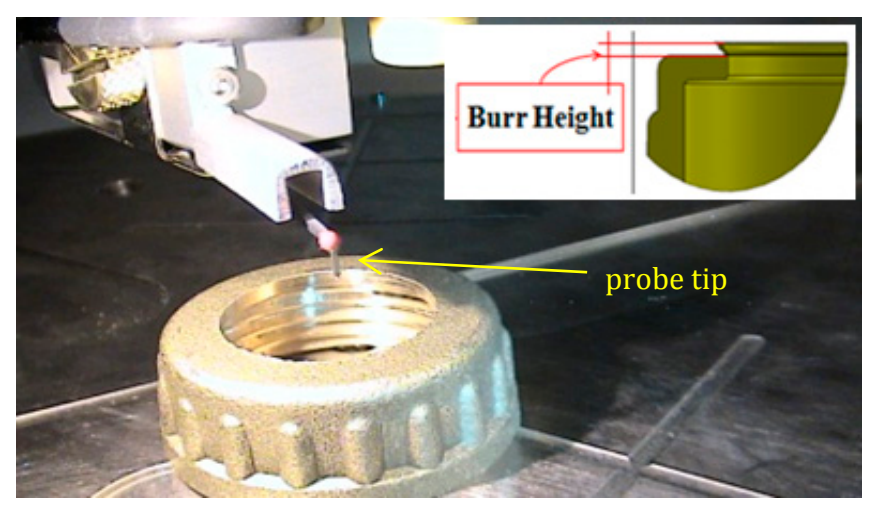

Figure 3. Burr height measuring instrument and schematic diagram of burr height measurement on a workpiece.

The drilling performances of both drills were investigated by the Taylor's model fitting for tool life equations of both drills using the EBH data sets. The Taylor's model is expressed as:

$$
S(T)^{n}(f)^{m}=c
$$

Hence,

$$
n \log T+m \log f+\log S=\log c
$$


where $S$ denotes cutting speed, $T$ represents tool life, $f$ indicates feed rate. The constants of $n, m$ and $c$ are determined using Taylor's model fitting to the observations during drilling of the water-valve workpieces with both drills.

Monte Carlo simulation is a sampling experiment whose objective is to estimate the distribution of an outcome factor that depends on several probabilistic input factors [22]. Monte Carlo simulation was used to assess the uncertainties of various applications such as a life prediction model of a fishing net weaving machine component [23], rotary axis error calibration of five-axis machine tool [24], measurement uncertainty of an $\mathrm{H}$-drive stage with air bearing in the semiconductor manufacturing industry [25], uncertainty on each of the eight link errors of a five-axis machine tools [26], verification of the effectiveness of the robust optimization approach for improving the machining accuracy retainability of the five-axis NC machine tool [27]. In this study, the Monte Carlo simulation technique was used to evaluate the tool life prediction uncertainty of the two drills. This technique involved normal probability distribution based on the Taylor's model. This technique was employed to perform random sampling from normal probability distribution by varying cutting speeds and feed rates within $\pm 5 \%$ of each factor for inputs at a confidence level of $95 \%$. The five cutting speeds $(40,45,50,55$ and $60 \mathrm{~m} / \mathrm{min})$ and four feed rates $(0.20,0.22,0.24$ and $0.26 \mathrm{~mm} / \mathrm{rev})$ were assigned as the inputs to generate random data sets for each factor by specifying mean for each factor and standard deviation for the variation of each factor based on the tool life models of the uncoated-WC and AlCrN coated-WC drills. Each factor generated a random data set of 10,000 that followed the normal distribution.

After drilling reaching the criterion of maximum EBH value of $0.16 \mathrm{~mm}$, the surfaces of the two drills were examined by scanning electron microscope (SEM: Hitachi Model S-3400N) at an accelerating voltage of $20 \mathrm{kV}$.

\section{Results}

Figure 4 presents averages EBH as functions of drilling time at the three cutting speeds and feed rates during drilling of the water-valve workpieces with the uncoated-WC drills. Figure 4a shows that the averages EBH upon drilling of the workpieces increased monotonically with increasing drilling time for all cutting speeds. The averages EBH at the three cutting speeds reached the criterion of $0.16 \mathrm{~mm}$ at the drilling time approximately $640 \mathrm{~min}$. On the other hand, Figure $4 \mathrm{~b}$ illustrates that the averages EBH increased rapidly with increasing drilling time within the range of approximately 200-500 min when drilling at a feed rate of $0.25 \mathrm{~mm} / \mathrm{rev}$ by keeping the cutting speed constant at $50 \mathrm{~m} / \mathrm{min}$. The averages EBH increased very slightly with increasing time within the range of approximately 70-650 min when drilling at a feed rate of $0.15 \mathrm{~mm} / \mathrm{rev}$ by keeping the cutting speed constant at $50 \mathrm{~m} / \mathrm{min}$ and increasing very rapidly after $650 \mathrm{~min}$. The result also showed that at the criterion of $0.16 \mathrm{~mm}$, the drilling time increased two times when drilling at the feed rate of $0.15 \mathrm{~mm} / \mathrm{rev}$ compared to drilling at the feed rate of $0.25 \mathrm{~mm} / \mathrm{rev}$ by keeping the cutting speed constant at $50 \mathrm{~m} / \mathrm{min}$. The results indicated that drilling at a low feed rate decreased the averages EBH.

Figure $4 \mathrm{c}$ illustrates a relationship between averages EBH and drilling time at the three cutting speeds $(40,50$ and $60 \mathrm{~m} / \mathrm{min}$ ) by keeping the feed rate constant at $0.2 \mathrm{~mm} / \mathrm{rev}$ throughout the experiments during drilling of the workpieces with the $\mathrm{AlCrN}$ coated-WC drills. The results showed that averages EBH increased monotonically with increasing drilling time for all cutting speeds. The averages EBH at the three cutting speeds reached the criterion of $0.16 \mathrm{~mm}$ at the drilling time approximately $800 \mathrm{~min}$. This indicated that the average drilling time was reduced by approximately $25 \%$ during drilling of the workpieces until reaching the EBH criterion when using AlCrN coated-WC drills by varying the cutting speeds and keeping the feed rate constant at $0.2 \mathrm{~mm} / \mathrm{rev}$. 


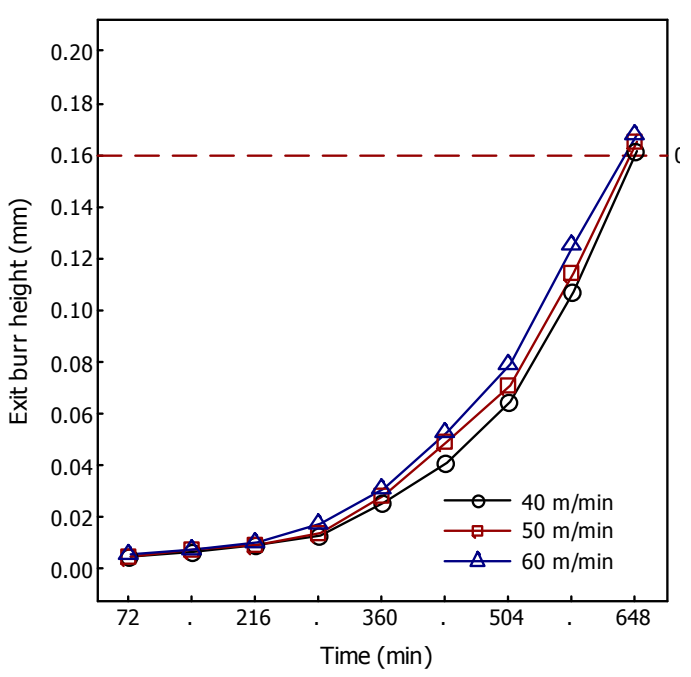

(a)

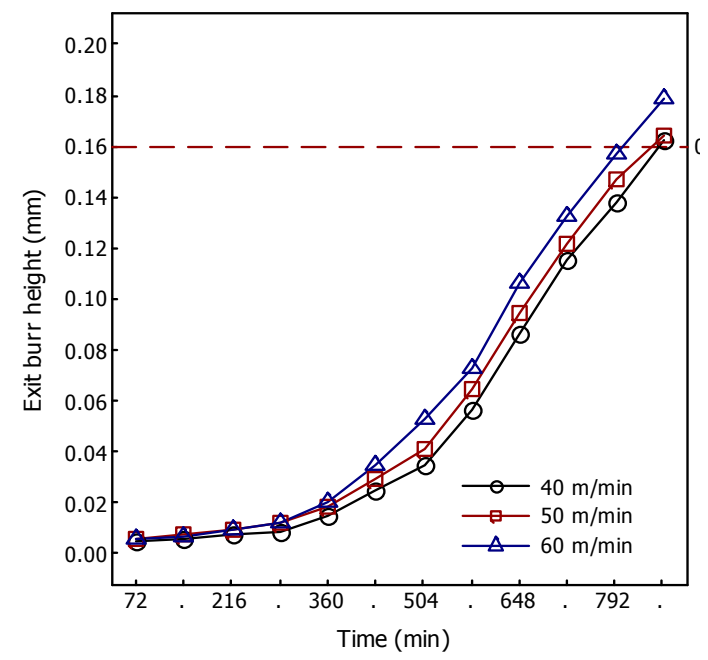

(c)

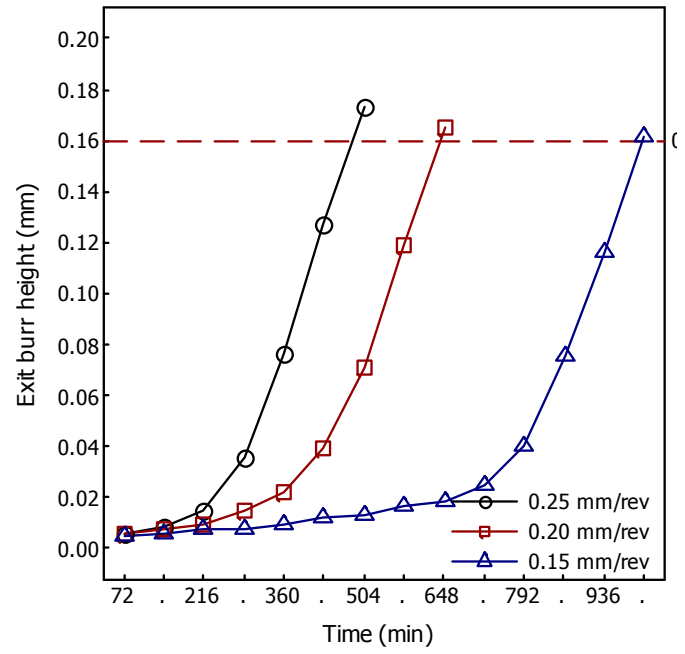

(b)

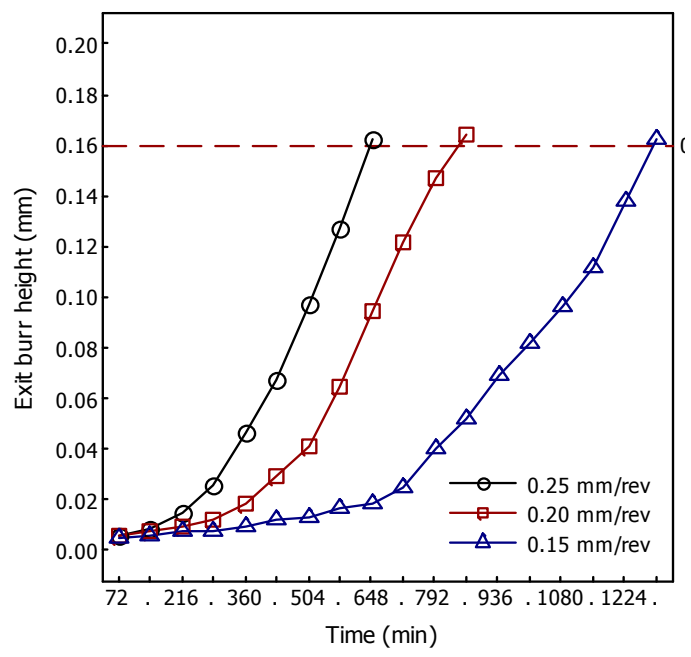

(d)

Figure 4. Average exit burr height versus drilling time using the uncoated-WC drills by varying (a) cutting speeds (keeping the feed rate constant at $0.2 \mathrm{~mm} / \mathrm{rev}$ ) and (b) feed rates (keeping the cutting speed constant at $50 \mathrm{~m} / \mathrm{min}$ ) and using AlCrN coated-WC drills by varying (c) cutting speeds and (d) feed rates.

Figure $4 \mathrm{~d}$ shows a relationship between averages EBH and drilling time at the three feed rates $(0.15$, 0.20 and $0.25 \mathrm{~mm} / \mathrm{rev}$ ) by holding the cutting speed constant at $50 \mathrm{~m} / \mathrm{min}$ all over the experiments. The results showed a dramatical variation in the averages EBH at the different feed rates versus drilling time. The averages EBH increased rapidly with increasing drilling time within the range of approximately 200-600 min when drilling at a feed rate of $0.25 \mathrm{~mm} / \mathrm{rev}$ by keeping the cutting speed constant at $50 \mathrm{~m} / \mathrm{min}$. The averages EBH increased very expeditiously with increasing time within the range of approximately $500-800 \mathrm{~min}$ when drilling at a feed rate of $0.2 \mathrm{~mm} / \mathrm{rev}$ and increasing very rapidly after $650 \mathrm{~min}$. On the other hand, the averages EBH increased very slightly with increasing time within the range of approximately $70-700 \mathrm{~min}$ when drilling at a feed rate of $0.15 \mathrm{~mm} / \mathrm{rev}$ and increasing rapidly after $700 \mathrm{~min}$. The results also illustrated that the drilling time increased two times when drilling at the feed rate of $0.15 \mathrm{~mm} / \mathrm{rev}$ by holding the cutting speed constant at $50 \mathrm{~m} / \mathrm{min}$ compared to drilling at the feed rate of $0.25 \mathrm{~mm} / \mathrm{rev}$ by evaluating at the criterion of $0.16 \mathrm{~mm}$. The results also indicated that drilling with a low feed rate decreased the average EBH.

According to the results of variations in the averages EBH at the three different feed rates versus drilling time using the two different drills, the drilling time increased approximately 1.5 times when 
drilling with the $\mathrm{AlCrN}$ coated-WC drills compared to drilling with the uncoated ones before reaching the EHB criterion of $0.16 \mathrm{~mm}$. This could be probably attributed to the reduction in cutting temperature, prevention of the different wear occurring at the tool surface, increasing hardness and wear resistance and decreasing coefficient of friction by applying the thin film coating on the cutting tools $[28,29]$.

Tables 2 and 3 show the results of drilling time at the three cutting speeds and feed rates corresponding to the EBH criterion for carrying out the drilling experiments using the uncoated-WC and the AlCrN coated-WC drills, respectively.

Table 2. Drilling time at the three cutting speeds and feed rates corresponding to the EBH criterion for carrying out the drilling experiments using the uncoated WC drills.

\begin{tabular}{ccc}
\hline Factor & Level & Drilling Time (min) \\
\hline Cutting speed $(\mathrm{m} / \mathrm{min})$ & 40 & 625 \\
(Feed rate was fixed at $0.2 \mathrm{~mm} / \mathrm{rev})$ & 50 & 620 \\
& 60 & 600 \\
\hline Feed rate $(\mathrm{mm} / \mathrm{rev})$ & 0.15 & 1010 \\
(Cutting speed was hold constant & 0.20 & 620 \\
at 50 m/min) & 0.25 & 450 \\
\hline
\end{tabular}

Table 3. Drilling time at the three cutting speeds and feed rates corresponding to the EBH criterion for carrying out the drilling experiments using the AlCrN coated WC drills.

\begin{tabular}{ccc}
\hline Factor & Level & Drilling Time (min) \\
\hline Cutting speed $(\mathrm{m} / \mathrm{min})$ & 40 & 857 \\
(Feed rate was fixed at $0.2 \mathrm{~mm} / \mathrm{rev})$ & 50 & 850 \\
& 60 & 803 \\
\hline Feed rate $(\mathrm{mm} / \mathrm{rev})$ & 0.15 & 1289 \\
(Cutting speed was hold constant & 0.20 & 850 \\
at 50 $\mathrm{m} / \mathrm{min})$ & 0.25 & 641 \\
\hline
\end{tabular}

The drilling time data sets at the EBH criterion of $0.16 \mathrm{~mm}$ were used to develop the tool life models of both drills by Taylor's equation. The tool life models in terms of cutting speed and feed rate were investigated based on Equation (2). The unknown constants of the models were calculated based on the Taylor's equation and the results in Tables 2 and 3. According to the results from Table 2, the unknown constant $(n)$ of the model for the uncoated-WC drills was obtained as follows:

$$
n \log 625+m \log 0.2+\log 40=\log c
$$

and

$$
n \log 600+m \log 0.2+\log 60=\log c
$$

According to Equations (3) and (4), the constant of $n$ was 9.9325. The unknown constant $(m)$ of the model for the uncoated-WC drills was estimated as follows:

$$
n \log 1010+m \log 0.15+\log 50=\log c
$$

and

$$
n \log 450+m \log 0.25+\log 50=\log c
$$

According to Equations (5) and (6), the constant of $m$ was 7.1855. Accordingly, the constant $c$ was $2.2375 \times 10^{24}$. Thus, the tool life model for the uncoated-WC drill was defined as:

$$
S\left(T_{1}\right)^{9.9325}(f)^{7.1855}=2.2375 \times 10^{24}
$$


where $T_{1}$ represents tool life for the uncoated-WC drill. Hence Equation (7) could be expressed as:

$$
T_{1}=\frac{282.8264}{S^{0.1007} f^{0.7234}}
$$

Similarly, according to the results from Table 3, the tool life model in terms of cutting speed and feed rate for the AlCrN coated-WC drill was defined as:

$$
S\left(T_{2}\right)^{6.2299}(f)^{8.3155}=1.1537 \times 10^{14}
$$

Equation (9) is represented as:

$$
T_{2}=\frac{180.7912}{S^{0.1605} f^{1.3348}}
$$

where $T_{2}$ represents tool life of the AlCrN coated-WC drill.

The tool life models of both drills were used to investigate the effects of cutting speed and feed rate on average tool life values. These models were valid for the value of EBH lower than 0.16 $\mathrm{mm}$. Equations (8) and (10) were used to predict tool life values during drilling of the forging brass workpieces with the uncoated-WC and the AlCrN coated-WC drills, respectively. Figure 5 shows the relationships between predicted tool life values and the cutting speed and feed rate during drilling of the workpieces with both drills. Figure 5 a illustrates the predicted values of tool life as a function of cutting speed. It could be seen that predicted tool life values of both drills varied almost linearly with cutting speed. Furthermore, predicted tool life values of both drills remained almost unchanged with increased in cutting speed by keeping the feed rate constant at $0.2 \mathrm{~mm} / \mathrm{rev}$. Figure $5 \mathrm{~b}$ depicts the predicted values of tool life as a function of feed rate. It could be seen that predicted tool life values of both drills varied sharply with feed rate. In addition, predicted tool life values of both drills decreased sharply with increased in feed rate by keeping the cutting speed constant at $50 \mathrm{~m} / \mathrm{min}$ for both drills. This indicated that feed rate had a stronger significant influence on predicted tool life than the cutting speed. It was also found that predicted tool life values of the AlCrN coated-WC drills were higher (approximately 1.5 times) than those of the uncoated-WC ones. The longer tool life of the AlCrN coated-WC drill was attributed to its synergistic hardness, strengthening and toughness mechanisms induced by the WC particles and CrN particles. Fox-Rabinovich et al. [30] reported that the presence of $\mathrm{Cr}$ and $\mathrm{Al}$ improves thermal stability that prevents particles removal by oxidation and abrasion. In addition, tool life of the coated drill could be enhanced by increasing tool surface hardness and segregation of the tool cutting edge from the severe cutting environment (high temperature and pressure) leading to the resistance of abrasive wear and oxidation of the hard-coated cutting tool $[14,31,32]$.

Based on Equations (8) and (10), Monte Carlo simulation technique was used to understand the impact of uncertainty in the prediction of tool life values when varying the cutting speeds and feed rates within $\pm 5 \%$ of each factor. Figure 6 illustrates an example of output results from Monte Carlo simulation based on the tool life model of an uncoated-WC drill when varying the cutting speeds and feed rates within $\pm 5 \%$ of each factor using the software Minitab ${ }^{\circledR}$ Version 16 [33]. The random data set of 10000 was generated from the normal distribution. The mean of the tool life was $596.59 \mathrm{~min}$ with $95 \%$ confidence intervals of 596.52 and $596.66 \mathrm{~min}$ while simulating tool life values at the cutting speed of $50 \mathrm{~m} / \mathrm{min}$ and the feed rate of $0.2 \mathrm{~mm} / \mathrm{rev}$. The standard deviation was $3.68 \mathrm{~min}$ with $95 \%$ confidence intervals of 3.63 and $3.73 \mathrm{~min}$. 


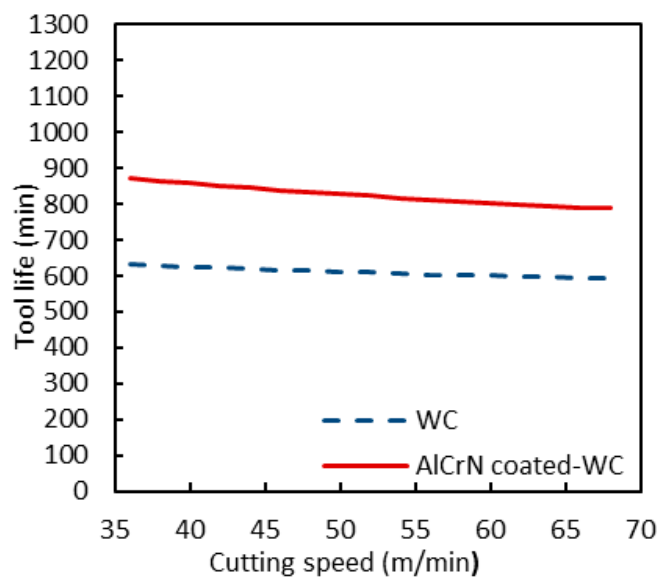

(a)

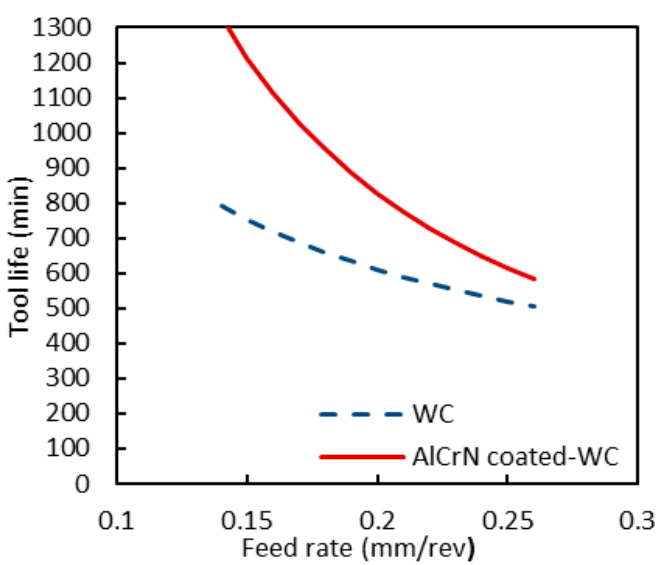

(b)

Figure 5. Plots of the relationships between predicted tool life values and (a) cutting speed (keeping the feed rate constant at $0.2 \mathrm{~mm} / \mathrm{rev}$ ) and (b) feed rate (keeping the cutting speed constant at $50 \mathrm{~m} / \mathrm{min}$ ) during drilling of the workpieces with both drills.

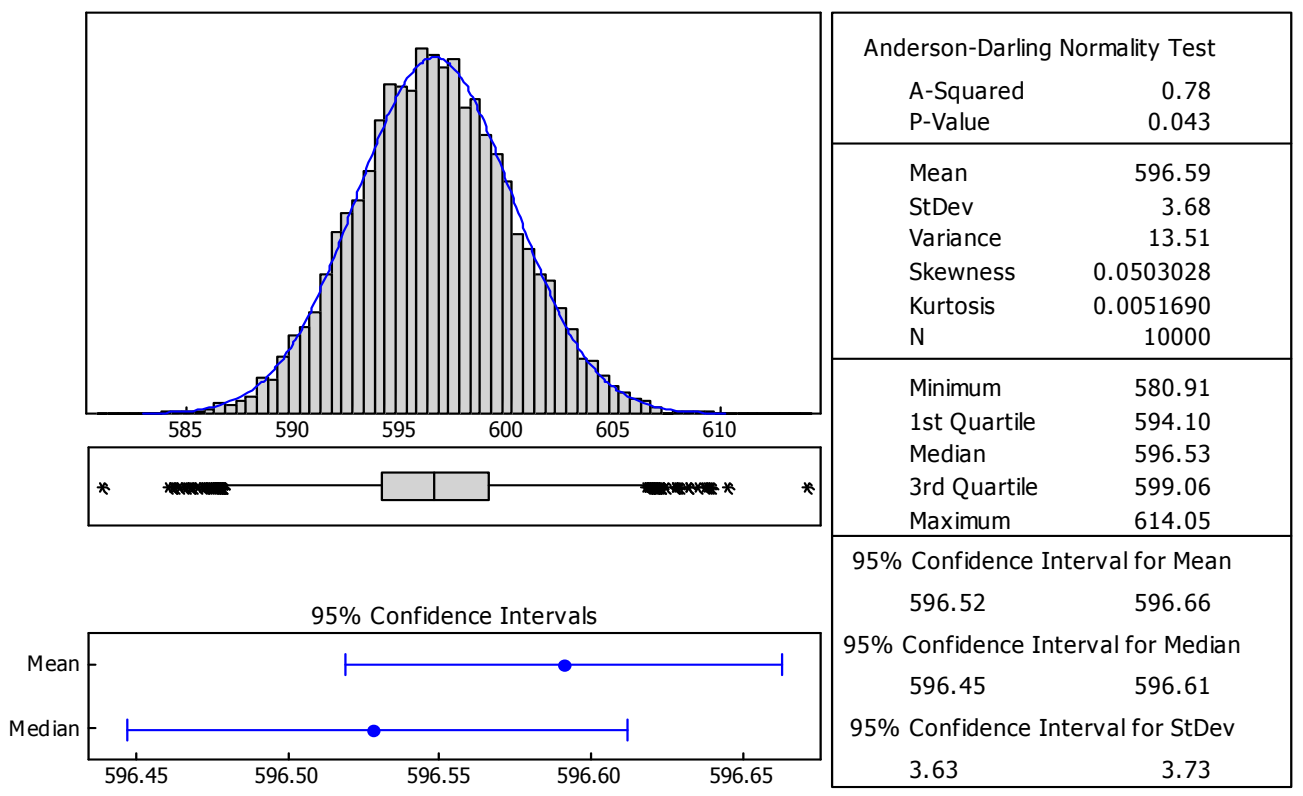

Figure 6. Output results from Monte Carlo simulation based on the tool life model of an uncoated-WC drill.

According to the Monte Carlo simulation results from the tool life models of both drills, Figures 7 and 8 graphically display the effects of cutting speed and feed rate on tool life for both drills when varying the cutting speeds and feed rates within $\pm 5 \%$ of each factor. Figure 7 shows that the $\mathrm{AlCrN}$ coated-WC drills had longer tool life than the uncoated-WC ones at most of the feed rates. Moreover, variations of tool life values at the feed rate of $0.2 \mathrm{~mm} / \mathrm{rev}$ for both drills were larger than those of tool life values at the rest levels. Figure 8 reveals that most of the tool life values of the AlCrN coated-WC drills were significantly higher than those of the uncoated-WC ones at feed rate in the range of $0.2-0.26 \mathrm{~mm} / \mathrm{rev}$. On the other hand, variations of tool life values at all cutting speeds corresponding to each feed rate were not different for both drills. This indicated that there were no statistically significant differences of tool life values while drilling of forging brass at the cutting speed in the range of 40-60 $\mathrm{m} / \mathrm{min}$ corresponding to each feed rate (overlapping of the intervals of tool life values for the cutting speed in the range of $40-60 \mathrm{~m} / \mathrm{min}$ at each feed rate). 


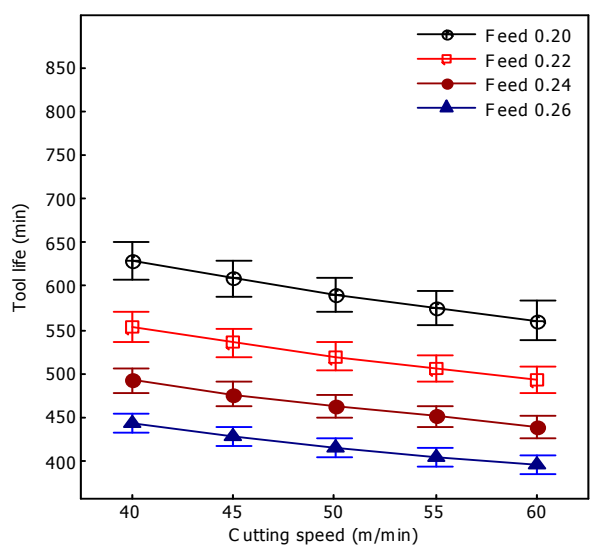

(a)

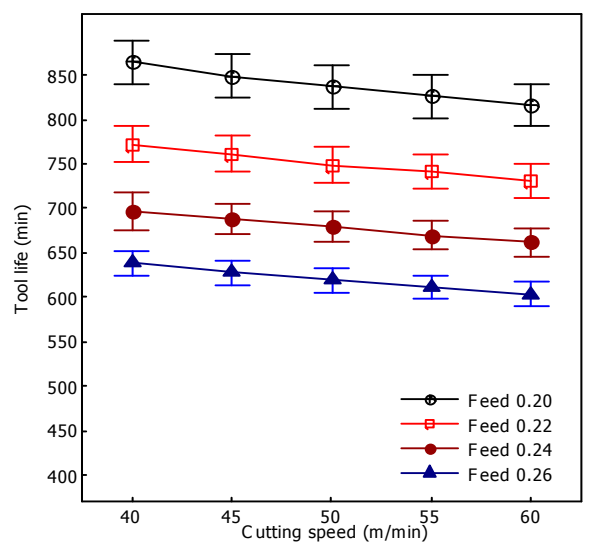

(b)

Figure 7. Effect of cutting speed on tool life for (a) the uncoated-WC and (b) the AlCrN coated-WC drills.

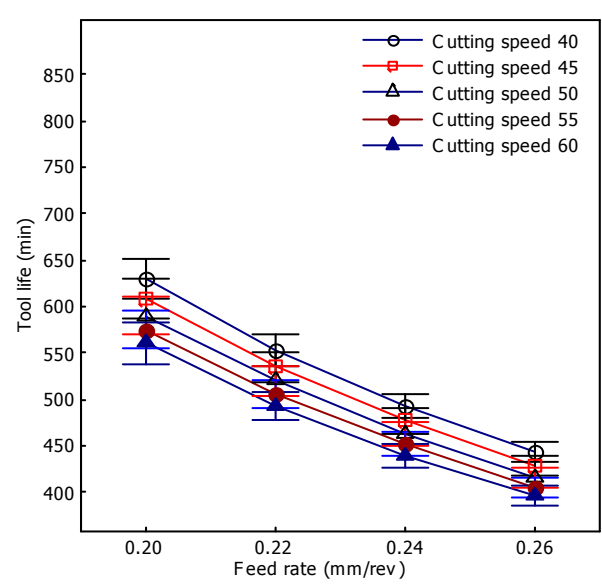

(a)

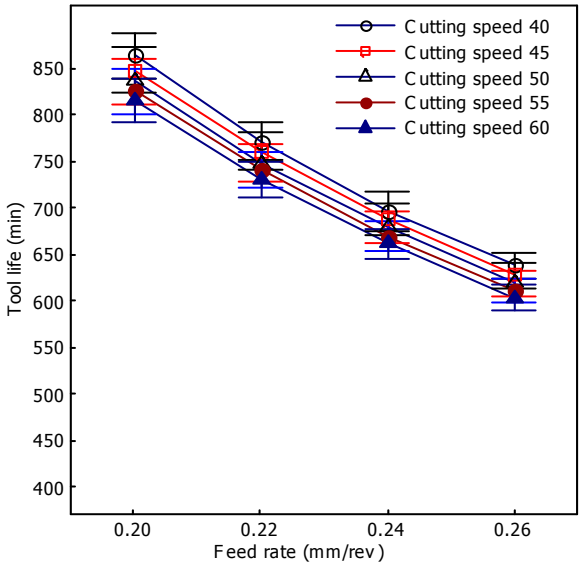

(b)

Figure 8. Effect of feed rate on tool life for (a) the uncoated-WC and (b) the AlCrN coated-WC drills.

Based on the EBH criterion and simulation results, the highest acceptable tool life values were obtained at the lowest feed rate $(0.2 \mathrm{~mm} / \mathrm{rev})$ and highest cutting speed $(60 \mathrm{~m} / \mathrm{min})$ during drilling of forging brass using the AlCrN coated-WC drill. At the high cutting speed and low feed rate, it was apparent for chips to evacuate along the hole axis due to shortened chip and coated drill contact based on low friction and high wear resistance of the AlCrN coated-WC drill. This result agreed with the previous study found in [15]. Although drilling at higher cutting speeds gave more productivity than drilling at lower cutting speeds, it resulted in accelerated tool wear or failure and higher EBH formation. Boopathi et al. [34] stated that higher cutting speeds could increase the frictional heat transfer between the drill and the workpiece, which in turn increased the temperature of the brass attaining the maximum value of $468^{\circ} \mathrm{C}$. It was also observed that higher feed rates required higher thrust force for the penetration of the workpiece. On the other hand, the thrust force decreased at the higher cutting speeds for constant feed rate. Hence this operating condition was recommended for manufacturers in drilling manufacturing industry based on the machine performance and its ability to produce a very large number of drilled parts. At this operating condition, the predicted tool life values of the uncoated-WC and the AlCrN coated-WC drills were approximately 600 and $800 \mathrm{~min}$, respectively based on estimates from the tool life models. This indicated that the coated drill increased tool life by $30 \%$.

Figure 9 shows SEM micrographs of an uncoated-WC drill and an AlCrN coated-WC one before and after drilling of the workpieces until reaching the criterion of EBH of $0.16 \mathrm{~mm}$. According to Figure $9 b$, the main wear mechanisms were chisel and outer corner wear. The chisel wear occurred in 
the region of the chisel edge because of high stress in the flow zone of the drill and workpiece interface. The outer corner wear was the critical failure mode because the thermal load was the highest. The tool wear rapidly increased leading to chipping occurring on the cutting edge of an uncoated-WC drill. Cutting force, thermal fatigue, torque and stress occurred on the drill when it moved along the hole axis to remove chips. Chipping on the tool could affect the quality of drilled holes and productivity degradation. In addition, the worn area of cutting edge produced high roughness and burr height of the drilled holes of the workpieces. However, the chipping occurring on the cutting edge can be resolved and reduced by using the coated drills. Coating materials can reduce the magnitude of cutting forces, torque and stresses. Since AlCrN coating has low thermal conductivity, friction coefficient and high thermal stability [14,30], it can reduce temperature between coated drill and chip resulting cutting force and stress reductions. According to Figure 9d, there were no visible crack and chipping formations on the surface of $\mathrm{AlCrN}$ coated-WC drill during drilling of the forging brass workpieces until reaching the $\mathrm{EBH}$ criterion of $0.16 \mathrm{~mm}$. The $\mathrm{AlCrN}$ coating deposited using magnetron sputtering, filtered cathodic arc (FCA) reduced the formation of the droplet phase and voids as well as provided high adhesive strength between the coating and the carbide substrate $[35,36]$. The AlCrN coating exhibited the best properties of abrasive, spalling, and adhesive wear resistances [37-39]. However, the adhesive wear could be caused by rubbing of a cutting edge of the drill against the workpiece surface by fast moving chip, as well as friction generated at a contact interface between the chips and the drill. The cutting edge was covered with a large amount of asperities of workpiece surface that could generate adhered layer. This result caused an undesirable increase of the EBH with the specification limit of $0.16 \mathrm{~mm}$.

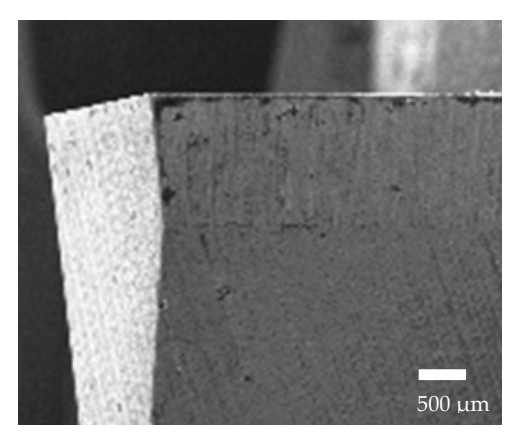

(a)

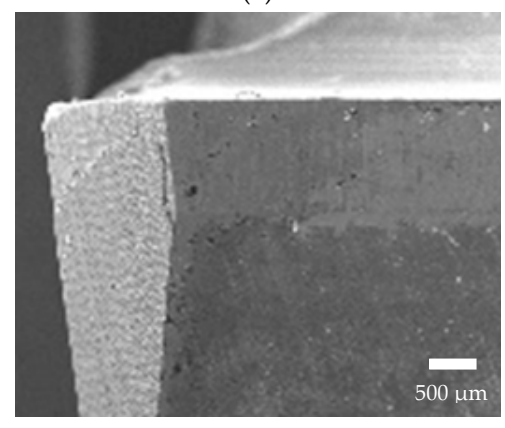

(c)

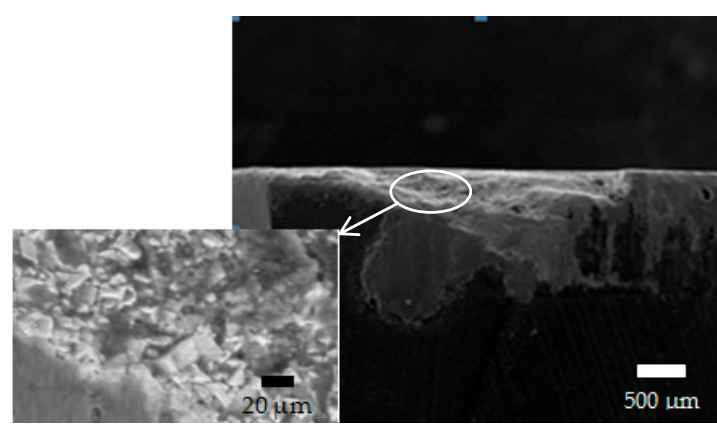

(b)

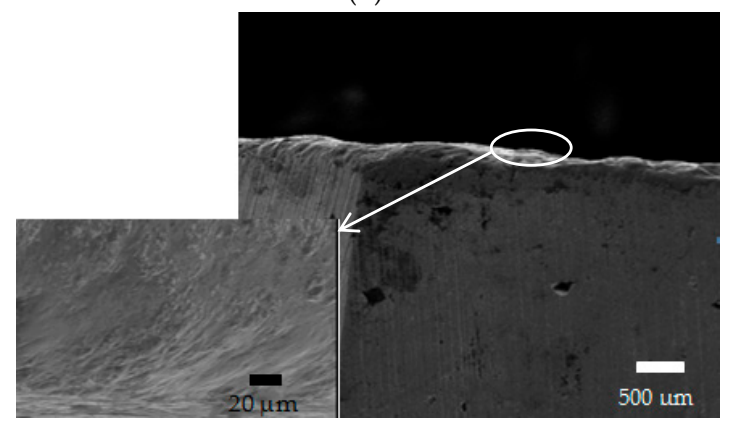

(d)

Figure 9. SEM images of (a) an uncoated-WC drill before and (b) after drilling of the workpieces (c) an AlCrN coated-WC drill before and (d) after drilling of the workpieces.

\section{Conclusions}

Tool life modelling based on Taylor's equation and Monte Carlo simulation technique has been successfully employed to investigate the effect and uncertainty of cutting speed and feed rate on averages EBH and tool life predictions while drilling of forging brass workpieces with the uncoated-WC and $\mathrm{AlCrN}$ coated-WC drills. The conclusions could be drawn as follows: 
- Feed rate affected averages EBH more strongly than cutting speed.

- The AlCrN coated-WC drill had better performance than the uncoated-WC one.

- Tool life of the AlCrN coated-WC drill at the criterion of EBH of $0.16 \mathrm{~mm}$ was higher (about 1.5 times) than that of the uncoated-WC one.

- The average drilling time was reduced by about $25 \%$ during drilling of the workpieces until reaching the EBH criterion when using the AlCrN coated-WC drills by varying the cutting speeds and keeping the feed rate constant at $0.2 \mathrm{~mm} / \mathrm{rev}$.

- Chipping occurred on the cutting edge of an uncoated-WC drill.

- The cutting speed of $60 \mathrm{~m} / \mathrm{min}$ and the feed rate of $0.2 \mathrm{~mm} / \mathrm{rev}$ were recommended for manufacturers in drilling of forging brass using the AlCrN coated-WC drill.

- The predicted tool life values of the uncoated-WC and the AlCrN coated-WC drills were approximately 600 and $800 \mathrm{~min}$, respectively at the recommended operating condition.

- The coated drill increased tool life by $30 \%$ during drilling of the forging brass workpieces at the cutting speed of $60 \mathrm{~m} / \mathrm{min}$ and the feed rate of $0.2 \mathrm{~mm} / \mathrm{rev}$.

Although using coated-WC drills can reduce burr height and increase tool life, drilling tool design can reduce burr height and prolong tool life leading to quality of drilled workpieces and productivity improvement. Sugita et al. [40] proposed a dedicated drill design of tool shape and nicked shape to reduce burr height and delamination and to increase the accuracy drilled holes during the drilling of composite materials. Hence, further research should be focused on tool design for burr height reduction and quality improvement of the drilling process for forging brass.

Author Contributions: M.T. carried out the experiments, collected the data sets, analyzed the data and wrote the manuscript; C.S. analyzed the data, wrote, edited and reviewed the manuscript.

Funding: This research was funded by the Faculty of Engineering, Khon Kaen University.

Acknowledgments: The authors gratefully acknowledge the Faculty of Engineering, Khon Kaen University for the financial supports of this research.

Conflicts of Interest: The authors declare no conflict of interest.

\section{References}

1. Wright, P.K.; Trent, E. Metals Cutting; Butterworth-Heinemann: Oxford, UK, 2000; ISBN 9780750670692.

2. Viktor, P.A. Geometry of Single-Point Turning Tools and Drills Fundamentals and Practical Applications; Springer: Berlin/Heidelberg, Germany, 2010.

3. de Paiva, J.M.F.; Amorim, F.L.; Soares, P.; Torres, R.D. Evaluation of hard coating performance in drilling compacted graphite iron (CGI). J. Mater. Eng. Perf. 2013, 22, 3155-3160. [CrossRef]

4. Wu, W.; Kuzu, A.; Stephenson, D.; Hong, J.; Bakkal, M.; Shih, A. Dry and minimum quantity lubrication high-throughput drilling of compacted graphite iron. Mach. Sci. Technol. 2018, 22, 652-670. [CrossRef]

5. Gillespie, L.K. The $\$ 2$ billion deburring bill. Manuf. Eng. Manag. 1975, 74, $20-21$.

6. Schafer, F. Deburring: Theory, Processes, Systems; Krausskopf Verlag: Mainz, Germany, 1975.

7. Toenshoff, H.K.; Spintig, W.; Koenig, W.; Neisses, A. Machining of holes developments in drilling technology. CIRP Ann. Manuf. Technol. 1994, 43, 551-561. [CrossRef]

8. Costa, E.S.; da Silva, M.B.; Machado, A.R. Burr produced on the drilling process as a function of tool wear and lubricant-coolant conditions. J. Braz. Soc. Mech. Sci. Eng. 2009, 31, 57-63. [CrossRef]

9. Lukic, L.; Djapic, M. Machinability parameters for optimal cutting process in flexible manufacturing systems. Metal. Int. 2012, 17, 10-16.

10. Shen, Q.; Lee, T.C.; Lau, W.S. Wear characteristics and flank wear model of the main cutting edges in spade drilling of ductile metals. Wear 1997, 208, 73-80. [CrossRef]

11. Astakhov, V.P.; Osman, M.O.M.; AlAta, M. Statistical design of experiments in metal cutting 2 Applications. J. Test. Eval. 1997, 25, 328-336.

12. Timata, M.; Saikaew, C. Influences of spindle speed and feed rate on exit burr height and workpiece diameter in drilling forging brass. Solid State Phenom. 2018, 279, 67-71. [CrossRef] 
13. Gong, M.; Chen, J.; Deng, X.; Wu, S. Sliding wear behavior of TiAlN and AlCrN coatings on a unique cemented carbide substrate. Int. Refract. Met. Hard Mater. 2017, 69, 209-214. [CrossRef]

14. Mo, J.L.; Zhu, M.H.; Lei, B.; Leng, Y.X.; Huang, N. Comparison of tribological behaviours of AlCrN and TiAlN coatings-deposited by physical vapor deposition. Wear 2007, 263, 1423-1429. [CrossRef]

15. Tekaüt, İ.; Demir, H.; Şeker, U. Experimental analysis and theoretical modelling of cutting parameters in the drilling of AISI H13 steel with coated and uncoated drills. Tran. FAMENA 2018, 42, 83-96. [CrossRef]

16. Karnik, S.R.; Gaitonde, V.N.; Davim, J.P. A comparative study of the ANN and RSM modeling approaches for predicting burr size in drilling. Int. J. Adv. Manuf. Technol. 2008, 38, 868-883. [CrossRef]

17. Lin, T.R. Cutting behaviour using variable feed and variable speed when drilling stainless steel with TiN-coated carbide drills. Int. J. Adv. Manuf. Technol. 2002, 19, 629-636. [CrossRef]

18. Lin, T.R.; Shyu, R.F. Improvement of tool life and exit burr using variable feeds when drilling stainless steel with coated drills. Int. J. Adv. Manuf. Technol. 2000, 16, 308-313. [CrossRef]

19. Wang, X.; Huang, C.; Zou, B.; Liu, H.; Wang, J. Effects of geometric structure of twist drill bits and cutting condition on tool life in drilling 42CrMo ultrahigh-strength steel. Int. J. Adv. Manuf. Technol. 2013, 64, 41-47. [CrossRef]

20. Polli, M.L.; Cardoso, M.J. Effects of process parameters and drill point geometry in deep drilling of SAE 4144M under MQL. J. Braz. Soc. Mech. Sci. Eng. 2018, 40, 137. [CrossRef]

21. Cardoso, M.J.; Polli, M.L.; Pintaude, G. Wear analysis of PVD-coated twist drills under MQL. Ind. Lubr. Tribol. 2018, 70, 1664-1669. [CrossRef]

22. Evans, J.R.; Olson, D.L. Introduction to Simulation and Risk Analysis; Prentice Hall: Upper Saddle River, NJ, USA, 2002.

23. Prengela, H.G.; Jindal, P.C.; Wendt, K.H.; Santhanam, A.T.; Hegde, P.L.; Penich, R.M. A new class of high performance PVD coatings for carbide cutting tools. Surf. Coat. Technol. 2011, 139, 25-34. [CrossRef]

24. Ibaraki, S.; Ota, Y. A machining test to calibrate rotary axis error motions of five-axis machine tools and its application to thermal deformation test. Int. Mach. Tool Manuf. 2014, 86, 81-88. [CrossRef]

25. Liu, Y.; Yuan, M.; Cao, J.; Cui, J.; Tan, J. Evaluation of measurement uncertainty in H-drive stage during high acceleration based on Monte Carlo method. Int. Mach. Tool Manuf. 2015, 93, 1-9. [CrossRef]

26. Andolfatto, L.; Mayer, J.R.R.; Lavernhe, S. Adaptive Monte Carlo applied to uncertainty estimation in five axis machine tool link errors identification with thermal disturbance. Int. Mach. Tool Manuf. 2011, 57, 618-627. [CrossRef]

27. Cai, L.C.; Zhang, Z.; Cheng, Q.; Liu, Z.; Gu, P.; Qi, Y. An approach to optimize the machining accuracy retainability of multi-axis NC machine tool based on robust design. Precis. Eng. 2016, 43, 370-386. [CrossRef]

28. Lin, Y.J.; Agrawal, A.; Fang, Y. Wear progressions and tool life enhancement with AlCrN coated inserts in high-speed dry and wet steel lathing. Wear 2008, 264, 226-234. [CrossRef]

29. Srisattayakul, P.; Saikaew, C. Effects of hard and MoN-coated stainless steel on wear behavior and tool life model under two-body abrasion wear testing. Metalurgija 2017, 56, 371-374.

30. Fox-Rabinovich, G.S.; Beake, B.D.; Endrino, J.L.; Veldhuis, S.V.; Parkinson, R.; Shuster, L.S.; Migranov, M.S. Effect of mechanical properties measured at room and elevated temperatures on the wear resistance of cutting tools with TiAlN and AlCrN coatings. Surf. Coat. Technol. 2006, 200, 5738-5742. [CrossRef]

31. Bourhis, E.L.; Goudeau, P.; Staia, M.H.; Puchi-Cabrera, E.S. Mechanical properties of hard AlCrN-based coated substrates. Surf. Coat. Technol. 2009, 203, 2961-2968. [CrossRef]

32. Endrino, J.L.; Fox-Rabinovich, G.S.; Reiter, A.; Veldhuis, S.V.; Galindo, R.E.; Albella, J.M.; Marco, J.F. Oxidation tuning in AlCrN coatings. Surf. Coat. Technol. 2007, 201, 4505-4511. [CrossRef]

33. Minitab®Version 16.2.4; Minitab Inc.: State College, PA, USA, 2013.

34. Boopathi, M.; Shankar, S.; Manikandakumar, S.; Ramesh, R. Experimental investigation of friction drilling on brass, aluminium and stainless steel. Procedia Eng. 2013, 64, 1219-1226. [CrossRef]

35. Vereschaka, A.A.; Grigoriev, S.N. Study of cracking mechanisms in multi-layered composite nano-structured coatings. Wear 2017, 378, 43-57. [CrossRef]

36. Vereschaka, A.A.; Grigoriev, S.N.; Sitnikov, N.N.; Batako, A.D. Delamination and longitudinal cracking in multi-layered composite nanostructured coatings and their influence on cutting tool life. Wear 2017, 390, 209-219. [CrossRef]

37. Aihua, L.; Jianxin, D.; Haibing, C.; Yangyang, C.; Jun, Z. Friction and wear properties of TiN, TiAlN, AlTiN and CrAlN PVD nitride coatings. Int. J. Refract. Met. Hard Mater. 2012, 31, 82-88. [CrossRef] 
38. Mo, J.L.; Zhu, M.H.; Leyland, A.; Matthews, A. Impact wear and abrasion resistance of CrN, AlCrN and AlTiN PVD coatings. Surf. Coat. Technol. 2013, 215, 170-177. [CrossRef]

39. Birol, Y. Sliding wear of $\mathrm{CrN}, \mathrm{AlCrN}$ and AlTiN coated AISIH13 hot work tool steels in aluminium extrusion. Tribol. Int. 2013, 57, 101-106. [CrossRef]

40. Sugita, N.; Shu, L.; Kimura, K.; Arai, G.; Arai, K. Dedicated drill design for reduction in burr and delamination during the drilling of composite materials. CIRP Ann. Manuf. Technol. 2019, 68, 89-92. [CrossRef] 